\title{
Safety of Overnight Hospitalization after Transurethral Resection of Prostate
}

\author{
Sarwar N. Mahmood*, Ismaeel Aghaways \\ Department of Surgery, Faculty of Medical Sciences, School of Medicine, University of Sulaymaniyah, \\ Sulaymaniyah, Iraq \\ Email: "sarwar.mahmood@univsul.edu.iq
}

Received 4 December 2015; accepted 25 January 2016; published 28 January 2016

Copyright (C) 2016 by authors and Scientific Research Publishing Inc.

This work is licensed under the Creative Commons Attribution International License (CC BY). http://creativecommons.org/licenses/by/4.0/

(c) () Op Open Access

\begin{abstract}
Background: Monopolar transurethral resection of prostate has long been a standard method of managements of benign prostatic hyperplasia. The safe and superior efficacy of transurethral resection of prostate (TURP) always argues strongly for maintaining it as the primary mode of therapy for patients with benign prostatic hyperplasia (BPH). There is a trend toward early catheter removal after transurethral resection of prostate (TURP) even to the extent of performing it as a day case. We explored the safety and feasibility of early catheter removal and discharging the patient without catheter after TURP. Materials and methods: Forty patients who underwent monopolar TURP were included in a prospective study. The decision to remove catheters on the first morning after surgery was based on the color of the catheter effluent, absence of clots, normal vital signs and adequate urine output. Patients who voided successfully were discharged on the same day as catheter removal. Results: Among the forty patients whose catheters were removed on first postoperative day, 38 patients (95\%) voided successfully, and were discharged on the same day. However, two out of forty patients $(5 \%)$ were recatheterized due to urethral discomfort during micturition. The catheter was removed on the next day. Mean overall duration of catheterization was 18.36 hours, and overall length of patient hospitalization was 21.68 hours. Conclusions: Overnight hospitalization and early catheter removal after transurethral prostatectomy are an appropriate, safe and effective way of patient care with minimal morbidity.
\end{abstract}

\section{Keywords}

Benign Prostatic Hyperplasia, Catheter Removal, Length of Hospital Stay, Transurethral Resection of Prostate

"Corresponding author. 


\section{Introduction}

The prostate gland is the male organ most commonly affected with either benign or malignant neoplasms. Benign prostatic hyperplasia is an endemic disease in the male population and it is increased with age [1] [2].

Transurethral resection of prostate (TURP) is considered the reference standard in the surgical therapy of symptomatic bladder outlet obstruction (BOO) secondary to benign prostatic hyperplasia (BPH) [3]. It is characterized by immediate success, as it removes the obstructing tissue, and provides prolonged improvement of symptoms and voiding variables [4], and replaces open prostatectomy as the procedure of choice for more than $95 \%$ of patients [1] [5].

In recent years, further developments in the surgical treatment of bladder outlet obstruction have been developed, which include laser enucleation, transurethral vaporization, bipolar TURP, transrectal high intensity focused ultrasound and transurethral microwave thermotherapy. These new methods of treatment of bladder outlet obstruction have attempted to reduce morbidity and length of stay associated with traditional transurethral resection of the prostate [6].

Despite the availability of these options, TURP has remained an effective and widely used procedure worldwide. In the last 30 years, the mortality has decreased substantially to $<0.25 \%$ in contemporary series [7]. However, the morbidity of TURP has remained unchanged at $\approx 18 \%$, because BPH is a disease of older men, hence comorbid conditions are unavoidable. While, the morbidity related to hemorrhage, duration of catheterization and consequent hospital stay can be improved upon [7].

Improvement of endoscopic instruments and new high-frequency technology, anesthetic care and intraoperative monitoring of fluid and electrolyte decrease the existing morbidity of TURP and become an increasingly safe procedure [7] [8]. Cherrie et al. reported that disadvantage of transurethral prostate resection compared with many new treatments for benign prostatic hypertrophy (BPH) was the necessity for postoperative catheterization, which in turn prevented early postoperative discharge home [9] [10]. This disadvantage can be addressed by shortening the duration of postoperative catheterization [9] [11] [12].

Klimberg et al., Feldstein and Benson, Aslan et al. and Muller et al. reported TURP as a day-care surgery with early catheter removal and decreased the cost and morbidity [10] [12]-[14].

This study was aimed to assess the feasibility of early removal of catheter following TURP.

\section{Materials and Methods}

The study was conducted in the urology department of Sulaymania general teaching hospital between April and September 2009. Forty patients (mean age 64.78 years, range 50 - 80) who presented to the outpatient department with significant symptoms of BOO from BPH or retention of urine were included. Patients with bleeding diathesis or on anticoagulant therapy, patients with urethral stricture and prostate cancer were excluded.

All the patients selected for the study were fully evaluated before TURP, including an assessment of their symptoms using the AUA symptom score, digital rectal examination, renal function tests, PSA estimate, urine analysis and culture. Transabdominal ultrasound of the urinary tract to evaluate prostate size, postvoid residual volume, and for the presence of backpressure changes in the kidneys.

The patients were admitted on the morning of the surgery after overnight fasting. All were given one dose of prophylactic antibiotics.

Patients were placed in the lithotomy position. A standard TURP carried out using a continuous-flow resectoscope $26 \mathrm{Fr}$ and a single wire loop for resection, in a video-assisted endourological system. At the end of the TURP, a $20 \mathrm{~F}$ three-way Foley catheter was placed, the bulb inflated $(40 \mathrm{~mL})$ and the bladder irrigated continuously with normal saline (0.9\%). Resection time and weight of resected chips were recorded.

In the postoperative ward, patients were constantly monitored for pulse, blood pressure, color of catheter drainage and any other complications, e.g. clot retention, TUR syndrome, etc. Bladder irrigation was reduced as soon as feasible, depending on the color of the effluent. Irrigation was stopped when the drainage became clear as early as $4 \mathrm{~h}$ after TURP and was continued in patients with blood tinged drainage, until clear. When the catheter drainage was clear or pink, the catheter was removed and the duration of catheterization recorded. The patients were discharged after they could pass urine freely with a good stream two or three times.

Patients were followed as an outpatient closely to evaluate symptomatic improvement and/or the development of any complication.

Data analysis was performed using SPSS version 19.0 (Chicago, IL, USA). The results were presented as 
percentages and means $( \pm \mathrm{SD})$. The categorical/dichotomous variables were compared using chi-squared/Fisher’s exact test, and continuous variables were compared using unpaired $t$-test. A p $<0.05$ was considered significant

\section{Results}

In this prospective study forty patient were included with a mean (range) age of 64.78 (50 - 80) years. The mean duration of symptoms prior to TURP was 19.32 (1 - 120) months. Mean prostatic volume measured by transabdominal ultrasound was 60.52 (30 - 140) grams (ml).The mean (range) duration of resection was 36.68 (10 - 90) min, and the weight of prostate resected was 25.38 (5 - 65) grams. The mean overall duration of catheterization was 18.36 (12 - 25) hours and overall mean length of hospital stay was 21.68 (15 - 30) hours (Table 1).

The outcome was considered successful in 38 patients (95\%), as the catheter was removed successfully and they were discharged within $23 \mathrm{~h}$. while two out of forty (5\%) patients were recatheterized due to urethral discomfort during micturition, and the catheter was removed next day.

Patients age, duration of symptoms before TURP had no effect on the duration of catheterization ( $\mathrm{p}=0.169)$ $(p=0.262)$, neither on hospital stay after surgery $(p=0219)(p=0.182)$. On the other hand prostate volume, resection time significantly influence the duration of catheterization $(\mathrm{p}<0.01)(\mathrm{p}<0.01)$ and the duration of hospital stay after surgery $(\mathrm{p}<0.01)(\mathrm{p}<0.01)$. While weight of resected tissue extend the duration of catheterization ( $\mathrm{p}<0.01$ ) but had no impact on hospital stays after surgery $(\mathrm{p}=0.123)$ (Table 2).

Out of the forty patients, $40 \%$ found to have chronic urine retention and $20 \%$ had acute urine retention, while the reminder had lower urinary tract symptoms (LUTS).

Acute and chronic retention of urine found to have no impact duration of catheterization $(\mathrm{p}=0.435)(\mathrm{p}=$ $0.355)$, neither on hospital stay after surgery $(\mathrm{p}=0.331)(\mathrm{p}=0.131)$ (Table 3$)$.

Majority of patients were on prolonging medical treatments for BPH before TURP (88\%), while $12 \%$ of patients were not on medical treatments. And found to have no impact on duration of catheterization, neither on hospital stay after TURP $(p=0.732)(p=0.660)$ respectively (Table 4$)$.

No blood transfusion was required in any patient during or after surgery. There were no cases of TUR syndrome or capsular perforation. After catheter removal and patient discharge home, no readmission to hospital was required for reinsertion of catheter, for failure to void or for clot retention.

Table 1. descriptive statistics of variables.

\begin{tabular}{ccccc}
\hline Variables & Minimum & Maximum & Mean & Std. deviation \\
Age (years) & 50 & 80 & 64.78 & 6.926 \\
Duration of symptoms(months) prior to TURP & 1 & 120 & 19.32 & 23.179 \\
Size of prostate(ml) transabdominal ultrasound & 30 & 140 & 60.52 & 32.879 \\
Resection time, minutes & 10 & 90 & 36.68 & 21.711 \\
Weight of resected tissue, g & 5 & 65 & 25.38 & 15.554 \\
Catheterization time, hours & 12 & 25 & 18.36 & 2.991 \\
Hospital stay after surgery, hours & 15 & 30 & 21.68 & 3.872 \\
\hline
\end{tabular}

TURP: transurethral resection of prostate.

Table 2. Descriptive statistics of variables.

\begin{tabular}{|c|c|c|c|c|}
\hline Variables & $\begin{array}{l}\text { Catheterization time } \\
\text { mean } \pm \text { Std. deviation }\end{array}$ & $p$ value & $\begin{array}{c}\text { Hospital stays after surgery, hours } \\
\text { mean } \pm \text { Std. deviation }\end{array}$ & $p$ value \\
\hline $\begin{array}{c}\text { Age(years) } \\
64.78 \pm 6.926\end{array}$ & $18.36 \pm 2.991$ & 0.169 & $21.68 \pm 3.872$ & 0.219 \\
\hline $\begin{array}{l}\text { Duration of symptoms(months) } \\
19.32 \pm 23.179\end{array}$ & $18.40 \pm 3.022$ & 0.262 & $21.77 \pm 3.876$ & 0.182 \\
\hline $\begin{array}{l}\text { AUA size of prostate(ml) } \\
65.52 \pm 32.879\end{array}$ & $18.36 \pm 2.991$ & $\mathrm{p}<0.01$ & $21.68 \pm 3.872$ & $\mathrm{p}<0.01$ \\
\hline $\begin{array}{c}\text { Resection time(min) } \\
36.68 \pm 21.711\end{array}$ & $18.36 \pm 2.991$ & $\mathrm{p}<0.01$ & $21.68 \pm 3.872$ & $\mathrm{p}<0.01$ \\
\hline $\begin{array}{l}\text { Weigh of resected tissue, g } \\
25.38 \pm 15.554\end{array}$ & $18.36 \pm 2.991$ & $\mathrm{p}<0.01$ & $21.68 \pm 3.872$ & 0.123 \\
\hline
\end{tabular}


Table 3. catheter time and hospital stay after surgery with retention of urine.

\begin{tabular}{ccccc}
\hline Variables & $\begin{array}{c}\text { Catheter time after TURP, hours } \\
\text { mean } \pm \text { S.D }\end{array}$ & p value & Hospital stay after surgery, hours & p value \\
\hline $\begin{array}{c}\text { Acute retention } \\
\text { Yes }\end{array}$ & $17.67 \pm 1.118$ & & & 0.331 \\
No & $18.56 \pm 3.334$ & 0.435 & $20.56 \pm 2.351$ & \\
Chronic retention & & & & 0.131 \\
Yes & $18.91 \pm 3.132$ & & $22.81 \pm 4.430$ & \\
No & $18.00 \pm 2.904$ & 0.355 & $20.92 \pm 3.335$ & \\
\hline
\end{tabular}

TURP: transurethral resection of prostate.

Table 4. Catheter time and hospital stay after TURP with medical treatment.

\begin{tabular}{|c|c|c|c|c|}
\hline Variables & $\begin{array}{l}\text { Catheter time, hours } \\
\text { mean } \pm \text { S.D }\end{array}$ & $\mathrm{p}$ value & $\begin{array}{l}\text { Hospital stay after surgery, hours } \\
\text { mean } \pm \text { S.D }\end{array}$ & $\mathrm{p}$ value \\
\hline \multicolumn{5}{|c|}{ Medical treatment } \\
\hline No & $18.80 \pm 2.280$ & 0.732 & $22.40 \pm 0.894$ & 0.660 \\
\hline Yes & $18.30 \pm 3.102$ & & $21.57 \pm 4.125$ & \\
\hline
\end{tabular}

\section{Discussion}

The safe and superior efficacy of TURP always argues strongly for maintaining it as the primary method of therapy for patients with symptomatic BPH. Any methods to reduce the duration of stay would lead to enormous saving of health care resources [14].

Post-operative care of TURP includes prolonged bladder irrigation that immobilizes patient for long hours. The presence of catheter for many days increases the chances of stricture formation and is also a handicap for day-to-day activities of the patients. This also places the patient on financial loss as the long hospital stay prevents him to attend to his work [15].

The duration of postoperative hospitalization and indwelling urethral catheterization has been significantly reduced over the last decades [12] [13] [16].

This can be explained by advancement in surgical and anesthetic technique, and better perioperative care but strongest predictor is aggressive catheter management [12].

The duration of catheterization after TURP depend primarily on the colour of the catheter effluent at the end of TURP (clear or lightly tinged effluent). In the current study the duration of catheterization was less than 24 hours (mean: $18.36 \mathrm{hr}$ ). This was comparable with the studies conducted by Gordon [16] and Chander et al. [13], Agrawal et al. [17] in which the duration was less than $24 \mathrm{hr}$ (Table 5).

In our study the duration of hospital stay was less than 24 hours (mean: $21.68 \mathrm{~h}$ ), this is in consistent with Gordon [16], Chander et al. [13], and Klimberg et al. [12], reporting the duration of hospital stay of less than 24 hours. While this is in disagreement with other studies, in which the mean hospital stay was 2.8 - 5.3 days [17]-[20].

Table 5. comparison of results from various studies of TURP as day surgery.

\begin{tabular}{|c|c|c|c|c|c|}
\hline Study & No. & $\begin{array}{l}\text { Age } \\
\text { (year) }\end{array}$ & $\begin{array}{l}\text { Volume resected } \\
\text { (gram) }\end{array}$ & $\begin{array}{l}\text { Duration of catheterization in } \\
\text { hr }\end{array}$ & $\begin{array}{c}\text { Hospital stays in } \\
\text { hr }\end{array}$ \\
\hline Chander et al. [13] & 64 & 62.4 & 22.1 & 7.15 & 10.7 \\
\hline Gordon [16] & 58 & 68.4 & 12.58 & 6.54 & 13.9 \\
\hline $\begin{array}{l}\text { Klimberg I.W. et al. } \\
\text { [12] }\end{array}$ & 125 & 71 & 14.7 & 48 & outpatient \\
\hline Agarwal S.K. et al. [17] & 83 & 69.9 & 23.6 & $<24$ & 72 \\
\hline Dodds et al. [18] & 100 & 72 & 27 & $<24 / 36-40$ & $67.2 / 127.2$ \\
\hline Mc Loughlin et al. [21] & 150 & 70 & 17.2 & $72-120$ & outpatient \\
\hline Mamo G.J. et al. [19] & 127 & 69.8 & 29.3 & $21.5 / 45.4$ & 68.4 \\
\hline Present study & 40 & 64.78 & 25.38 & 18.36 & 21.68 \\
\hline
\end{tabular}


This difference may be attributed to improvements in anesthesia and operative technique that include maintaining meticulous hemostasis during operation and point coagulation of arterial bleeders.

In current study the duration of catheter removal was strongly correlated with two perioperative factors; the weight of resected prostatic chips and resection time ( $p$ value: $\mathrm{p}<0.01, \mathrm{p}<0.01$ ) respectively. Similar correlation reported by Chalise et al. [22], and Gordon [16], while Chander et al. [13] found no statistical correlation between either the volume of prostate resected or the duration of surgery with the duration of catheterization.

Out of forty cases, only two patient need recatheterization and both of them were successful in passing urine next day after catheter removal. Therefore the final success rate of early catheter removal less than 24 hours was (38/40; 95\%) in consistent with other studies Aslan et al. [12], Chander et al. [13], Tatsuo and Allan [23] in which successive rate were $93 \%, 98 \%, 96.3 \%$ respectively.

Small sample size was the major limitations of our study.

\section{Conclusion}

Overnight hospitalization and early catheter removal after transurethral prostatectomy are an appropriate, safe and effective way of patient care with minimal morbidity.

\section{References}

[1] Presti Jr., J.C., Kane, C.J., Shinohara, K. and Carroll, P.R. (2008) Neoplasms of the Prostate Glands Smith’s General Urology. $17^{\text {th }}$ Edition, McGraw Hill Medical, New York, 348-374

[2] Kirby, R.S. and McConnell, J. (2005) Benign Prostatic Hyperplasia. 5th Edition, Health Press (NM), London, UK.

[3] Gordon, N.S.I., Hadlow, G., Knight, E. and Mohan, P. (1997) Transurethral Prostatectomy: Still the Gold Standard. Australian and New Zealand Journal of Surgery, 67, 354-357. http://dx.doi.org/10.1111/j.1445-2197.1997.tb01991.x

[4] Flanigan, R.C., Reda, D.J., Wasson, J.H., Anderson, R.J., Abdellatif, M. and Bruskewitz, R.C. (1998) 5-Year Outcome of Surgical Resection and Watchful Waiting for Men with Moderately Symptomatic BPH. A Department of Veterans Affairs Cooperative Study. The Journal of Urology, 160, 12-16. http://dx.doi.org/10.1016/S0022-5347(01)63011-8

[5] Roehrborn, C.G. and Mcconnell, J.D. (2007) Benign Prostatic Hyperplasia: Etiology, Pathophysiology, Epidemiology, and Natural History. Campbell-Walsh Urology, 9th Edition, Saunders, Philadelphia.

[6] Neyer, M., Reissigl, A., Schwab, C., Pointner, J., Abt, D., Bachmayer, C., et al. (2013) Bipolar versus Monopolar Transurethral Resection of the Prostate: Results of a Comparative, Prospective Bicenter Study-Perioperative Outcome and Long-Term Efficacy. Urologia Internationalis, 90, 62-67. http://dx.doi.org/10.1159/000343688

[7] Madersbacher, S. and Marberger, M. (1999) Is Transurethral Resection of Prostate Still Justified? BJU International, 83, 227-237. http://dx.doi.org/10.1046/j.1464-410x.1999.00908.x

[8] Hartung, R., Leyh, H., Liapi, C., Fastenmeier, K., and Barba, M. (2001) Coagulating Intermittent Cutting. Improved High-Frequency Surgery in Transurethral Prostatectomy. European Urology, 39, 676-681. http://dx.doi.org/10.1159/000052526

[9] Cherrie, R.J., Young, R.A. and Cattolica, E.V. (1997) The Safety of Overnight Hospitalization for Transurethral Prostatectomy: A Prospective Study of 200 Patients. The Journal of Urology, 157, 531-533. http://dx.doi.org/10.1016/S0022-5347(01)65194-2

[10] Klimberg, I.W., Locke, D.R., Leonard, E., Madore, R. and Klimberg, S.R. (1994) Outpatient Transurethral Resection of the Prostate at a Urological Ambulatory Center. The Journal of Urology, 151, 1547-1549.

[11] Feldstein, M.S. and Benson, N.A. (1997) Early Catheter Removal and Reduced Length of Hospital Stay Following Transurethral Prostatectomy: A Retrospective Analysis of 100 Consecutive Patients. The Journal of Urology, 140, 532-534.

[12] Aslan, G., Celebi, I., Arslan, D. and Esen, A.A. (2002) Early Catheter Removal Following Transurethral Prostatectomy: Overnight Catheterization. Urologia Internationalis, 68, 105-108.

[13] Chander, J., Vanitha, V., Lal, P. and Ramteke, V.K. (2003) Transurethral Resection of the Prostate as Catheter-Free Day-Care Surgery. BJU International, 92, 422-425. http://dx.doi.org/10.1046/j.1464-410X.2003.04364.X

[14] Mueller, E.J., Zeidmann, E.J., Desmond, P.M., Thompson, I.M., Optenberg, S.A. and Wasson, J. (1996) Reduction of Length of Stay and Cost of Transurethral Resection of the Prostate by Early Catheter Removal. British Journal of Urology, 78, 893-896. http://dx.doi.org/10.1046/j.1464-410X.1996.01614.x

[15] Khan, A. (2014) Day Care Monopolar Transurethral Resection of Prostate: Is It Feasible? Urology Annals, 6, $334-339$. http://dx.doi.org/10.4103/0974-7796.140998 
[16] Gordon, N.S.I. (1998) Catheter-Free Same Day Surgery Transurethral Resection of the Prostate. The Journal of Urology, 160, 1709-1712. http://dx.doi.org/10.1016/S0022-5347(01)62390-5

[17] Agrawal, S.K. and Kumar, A.S. (1993) Early Removal of Catheter Following Transurethral Resection of the Prostate. British Journal of Urology, 72, 928-998.

[18] Dodds, L., Lawson, P.O., Crosthwaite, A.H. and Wells, G.R. (1995) Early Catheter Removal. A Prospective Study of 100 consecutive Patients Undergoing Transurethral Resection of the Prostate. British Journal of Urology, 75, 755-779. http://dx.doi.org/10.1111/j.1464-410X.1995.tb07386.x

[19] Mamo, G.J. and Cohen, S.P. (1991) Early Catheter Removal versus Conventional Practice in Patients Undergoing Transurethral Resection of Prostate. Urology, 37, 519-522. http://dx.doi.org/10.1016/0090-4295(91)80315-X

[20] Klimberg, I.W., Locke, D.R., Leonard, E., Madore, R. and Klimberg, S.R. (1994) Outpatient Transurethral Resection of the Prostate at a Urological Ambulatory Center. The Journal of Urology, 151, 1547-1915.

[21] McLoughlin, M.G. and Kinahan, T.J. (1990) Transurethral Resection of the Prostate in the Outpatient Setting. The Journal of Urology, 143, 951-952.

[22] Chalise, P.R., Agrawal, C.S. and Pandit, R.K. (2007) Reduction of Length of Hospital Stay after Transurethral Resection of Prostate by Early Catheter Removal: A Retrospective Analysis. Nepal Medical College Journal, 9, 84-87.

[23] Nakagawa, T. and Toguri, A.G. (2006) Early Catheter Removal Following Transurethral Prostatectomy: A Study of 431 Patients. Medical Principles and Practice, 15, 126-130. http://dx.doi.org/10.1159/000090917

\author{
Abbreviations and Acronyms \\ $\mathrm{BPH}=$ benign prostatic hyperplasia \\ TUR $=$ transurethral resection \\ TURP $=$ transurethral resection of prostate \\ $\mathrm{m}$-TURP $=$ Monopolar transurethral resection of prostate \\ $\mathrm{BOO}=$ bladder outlet obstruction
}

